Check for updates

Cite this: RSC Adv., 2018, 8, 13513

Received 6th February 2018

Accepted 5th April 2018

DOI: $10.1039 / c 8 \mathrm{ra01182f}$

rsc.li/rsc-advances

\section{Towards controlling the crystallisation behaviour of fenofibrate melt: triggers of crystallisation and polymorphic transformation $\uparrow$}

\author{
Pratchaya Tipduangta, (D) ${ }^{\text {ac }}$ Khaled Takieddin, ${ }^{a}$ László Fábián, (D) a Peter Belton ${ }^{b}$ \\ and Sheng Qi $\mathbb{D}$ *a
}

Fenofibrate (FEN) is a dyslipidemia treatment agent which is poorly soluble in water. FEN has tendency to form polymorphs and its crystallisation behaviour is difficult to predict. The nucleation process can be initiated by mechanical disruption such as ball milling or surface scratching which may result in different crystallisation behaviour to that observed in the unperturbed system. This study has obtained insights into the controllability of FEN crystallisation by means of regulating the exposed surface and growth temperatures during its crystallisation. The availability of an open top surface (OTS) during the crystallisation of the FEN melt resulted in a mixture containing FEN form I and IIa (I $\gg \mid \mathrm{Ila})$ at room temperature, and in the range 40 to $70{ }^{\circ} \mathrm{C}$. Covering the surface led to significant increases in the yield of form Ila at room temperature and at 40 and $50{ }^{\circ} \mathrm{C}$. These temperatures also yielded the highest amount of form Ila in the OTS samples whilst crystallisation at $70{ }^{\circ} \mathrm{C}$ led to only FEN form I crystals regardless of the availability of the free surface. The metastable FEN form Ila transforms to the stable form I under the influence of a mechanical stress. Additionally, the introduction of OTS before the completion of crystallisation of form lla led to a 'switch' of from lla growth to form I. This study demonstrates that the polymorph selection of FEN can be obtained by the manipulation of the crystallisation conditions.

\section{Introduction}

Fenofibrate (propan-2-yl 2-(4-[(4-chlorophenyl)carbonyl] phenoxy)-2-methylpropanoate) has been prescribed to treat hypercholesterolemia since $1970 .^{1}$ It is a prodrug in which fenofibric acid is the active form. The pharmacological effect of fenofibrate (FEN) is to reduce low-density lipoprotein (LDL) and increase high-density lipoprotein (HDL) by binding to peroxisome proliferator-activated receptor alpha (PPAR $\alpha){ }^{\mathbf{1}, 2}$ FEN is categorised as a BCS class II drug because of its poor aqueous solubility $\left(0.8 \mu \mathrm{g} \mathrm{ml}^{-1}\right)$, but it has a high permeability (>90\%) through lipid membranes., ${ }^{3,4}$ To overcome the solubility issue, particle size reduction (micronized and nanocrystals) and lipid dispersions have been used in the commercialised formulations containing FEN. ${ }^{1}$ With the increased use of the amorphous state of the drug in dispersion based formulations, ${ }^{5-8}$ it is extremely

\footnotetext{
${ }^{a}$ School of Pharmacy, University of East Anglia, Norwich, Norfolk, NR4 7TJ, UK. E-mail: sheng.qi@uea.ac.uk

${ }^{b}$ School of Chemistry, University of East Anglia, Norwich, Norfolk, NR4 7TJ, UK

${ }^{c}$ Department of Pharmaceutical Sciences, Faculty of Pharmacy, Chiang Mai University, Chiang Mai, Thailand 50200

$\dagger$ Electronic supplementary information (ESI) available. CCDC 1822341. For ESI and crystallographic data in CIF or other electronic format see DOI: 10.1039/c8ra01182f
}

important to fully understand the stability and crystallisation behaviour of amorphous FEN. Zhou and co-workers have conducted a systematic study of a range of low-molecular weight drugs including $\mathrm{FEN}^{9}$ probing the relationship between physical stability and a range of thermodynamic properties. They identified two important properties: molecular mobility, which is a measure of the rate of cooperatively rearrangement in subsystems in the amorphous state, and configurational entropy, which is the entropy difference between the disordered state and the crystalline state. The study revealed that the molecules that have high configurational entropies and low molecular mobilities were the least likely to spontaneously crystallise. ${ }^{9}$ In amorphous FEN the configurational entropy had a relatively high value of $76.6 \mathrm{~J} \mathrm{~mol}^{-1} \mathrm{~K}^{-1}$ (relative to form I), but it also exhibited a relatively high molecular mobility value of $72.3 \times 10^{-5} \mathrm{~s}^{-1} .9$ The high molecular mobility can possibly be attributed to weak intermolecular interactions, ${ }^{\mathbf{1 0 , 1 1}}$ which results in the low probability of FEN molecules forming stable nuclei and heterogeneous nucleation is the main route to initiate the crystallisation. ${ }^{12}$ Heterogeneous nucleation triggers, including scratching the surface or placing an FEN seed on the surface of amorphous FEN, resulted in an immediate initiation of crystallisation. ${ }^{12}$

Three FEN polymorphs have been documented in the Cambridge Structural Database (CSD). The stable form I (with a melting point at $80{ }^{\circ} \mathrm{C}$ ) is the standard polymorph used as API in 
commercial tablets and capsules. Form I can be obtained by a slow solvent evaporation method. ${ }^{13}$ The metastable form called form II was reported by Di Martino et al. and Heinz et al. ${ }^{14-16}$ It was produced by the recrystallization of amorphous FEN from the melt. The melting point of the product was $74{ }^{\circ} \mathrm{C}$. It converts to the stable form I during heating via melt recrystallization and melts again at $80{ }^{\circ} \mathrm{C} .{ }^{\mathbf{1 4 - 1 6}}$ Balendiran and co-workers reported the single crystal structure of a FEN form they called form II. It was recrystallised by a solvent (ethanol) evaporation method, but no melting point and spectroscopic data were reported. ${ }^{17}$ However, it is not clear that the two types of form II are the same. In order to avoid confusion, the FEN form II from Di Martino et al. and Heinz et al. will be addressed as FEN form IIa in this study and the one from Balendiran will be addressed as form IIb. Form III was first reported by additive induced crystallisation using talc and it is not possible to crystallise it in isolation as pure form. ${ }^{11}$ The characteristic data of all the metastable FEN forms available from the literature: IIa, IIb and III are summarised in Table 1.

This study aims to investigate the effect of the availability of an open top surface (OTS) and variations in incubation temperature on the crystallisation behaviour of FEN melt. There is good evidence that allowing crystallisation to proceed from the melt in an unconstrained manner (the so called free surface) can increase the rates of crystal growth in drugs such as nifedipine, indomethacin, and griseofulvin..$^{18-21}$ This increased growth rate is thought to be due to higher molecular mobility at free surfaces. ${ }^{18-21}$ Increasing numbers of pharmaceutically related molecules have been reported to exhibit surface-induced polymorph selection behaviour when crystallised from solvents and subjected to different solid substrate surfaces. ${ }^{22-25}$ However, little has been reported in terms of whether the free surface has an impact on polymorph selection of the crystals obtained from melt-cooled amorphous materials. Furthermore, the temperature during crystallisation is another important factor that influences the formation of crystal polymorphs. ${ }^{26}$ Therefore this study further investigated the combined effect of growth temperature and availability of free surface on the crystallisation behaviour of amorphous FEN. As the homogeneous nucleation of amorphous FEN is a slow process, ${ }^{12,27}$ the heterogeneous nucleation and crystallisation of FEN was initiated by scratching the surface of amorphous FEN using a metal spatula.

\section{Materials and methods}

\section{Materials}

Crystalline FEN form I was kindly donated by Merck Serono, Germany. Glass slides and coverslips $24 \times 24 \mathrm{~mm}$, thickness
0.16-0.18 $\mathrm{mm}$ were purchased from Academy Science Limited (Kent, UK).

\section{Preparation of FEN crystallisation samples}

Approximately 3-5 $\mathrm{mg}$ of crystalline FEN form I powder was placed on a glass slide and heated on a hot plate at $100{ }^{\circ} \mathrm{C}$ until it was completely molten. The glass slide was immediately removed from the hot plate to allow the sample to cool to room temperature. The surface disruption technique, involving the use of a stainless-steel spatula to scratch the surface of the amorphous FEN, was used to induce crystallisation. After surface scratching either of two procedures was followed. In the first, a cover slip was immediately placed on top of the sample to sandwich the drug between the glass slide and the cover slip (these samples are referred to as "bulk crystalline FEN samples" or B-FEN in this study). The second set of scratched samples were left to crystallise with an OTS (these samples are referred to as "free surface crystalline FEN samples" or FS-FEN). In these samples, where it was possible, examination was made of the top and bottom layers of the material separately. Immediately after the initiation of crystallisation by surface scratching, both B-FEN and FS-FEN samples were incubated in an oven at 40, 50, 60 or $70{ }^{\circ} \mathrm{C}$ for $30 \mathrm{~min}$ to obtain complete crystallisation. The storage stability studies of B-FEN and FS-FEN were conducted by storing the samples at ambient temperature in sealed glass vials for up to 6 months. For the storage stability of B-FEN samples, once the crystallisation was completed, the top cover slip was carefully removed prior to the storage.

\section{Differential scanning calorimetry (DSC)}

A DSC Q2000 TA (New Castle, USA) which was equipped with an RSC 90 cooling unit was used. Full temperature and heat capacity calibrations were performed prior to the sample measurement. The scanning rate used was $10{ }^{\circ} \mathrm{C} \mathrm{min}^{-1}$ over a temperature range of $-60{ }^{\circ} \mathrm{C}$ to $120{ }^{\circ} \mathrm{C}$. For isothermal modulated temperature DSC (MTDSC) at 60 and $70{ }^{\circ} \mathrm{C}$ for 120 minutes, the amplitude of $\pm 2{ }^{\circ} \mathrm{C}$ with a period of 60 seconds was used for all measurements. The dry nitrogen was purged at $50 \mathrm{ml} \mathrm{min}{ }^{-1}$. Between 1 and $3 \mathrm{mg}$ of samples was weighed out accurately and encapsulated in TA standard crimped pans. All measurements were performed in triplicate.

\section{Polarised light microscopy (PLM) and hot-stage polarised light microscopy (HS-PLM)}

PLM model Leica DM LS2 (Wetzlar GmbH, Germany) equipped with a JVC camera with 5,10 and $20 \times$ magnification was used to

Table 1 Summary of the available literature data related to metastable FEN form II and III

\begin{tabular}{lllll}
\hline Characteristic data of FEN form II & $\begin{array}{l}\text { Assignment by } \\
\text { the authors }\end{array}$ & References & $\begin{array}{l}\text { Characteristic data } \\
\text { of FEN form III }\end{array}$ & $\begin{array}{l}\text { Assignment by } \\
\text { the authors }\end{array}$ \\
\hline DSC $\left(T_{\mathrm{m}}\right.$ at $\left.74{ }^{\circ} \mathrm{C}\right)$ & IIa & 14,16 & DSC $\left(T_{\left.\mathrm{m} \text { at } 50{ }^{\circ} \mathrm{C}\right)}\right.$ & III \\
PXRD pattern & IIa & 14 & PXRD pattern & III \\
Raman spectrum & IIa & 16 & FTIR spectrum & III \\
Single crystal & IIb & 17 & Single crystal & III
\end{tabular}


Table 2 Crystallographic parameters of known polymorphic forms of FEN

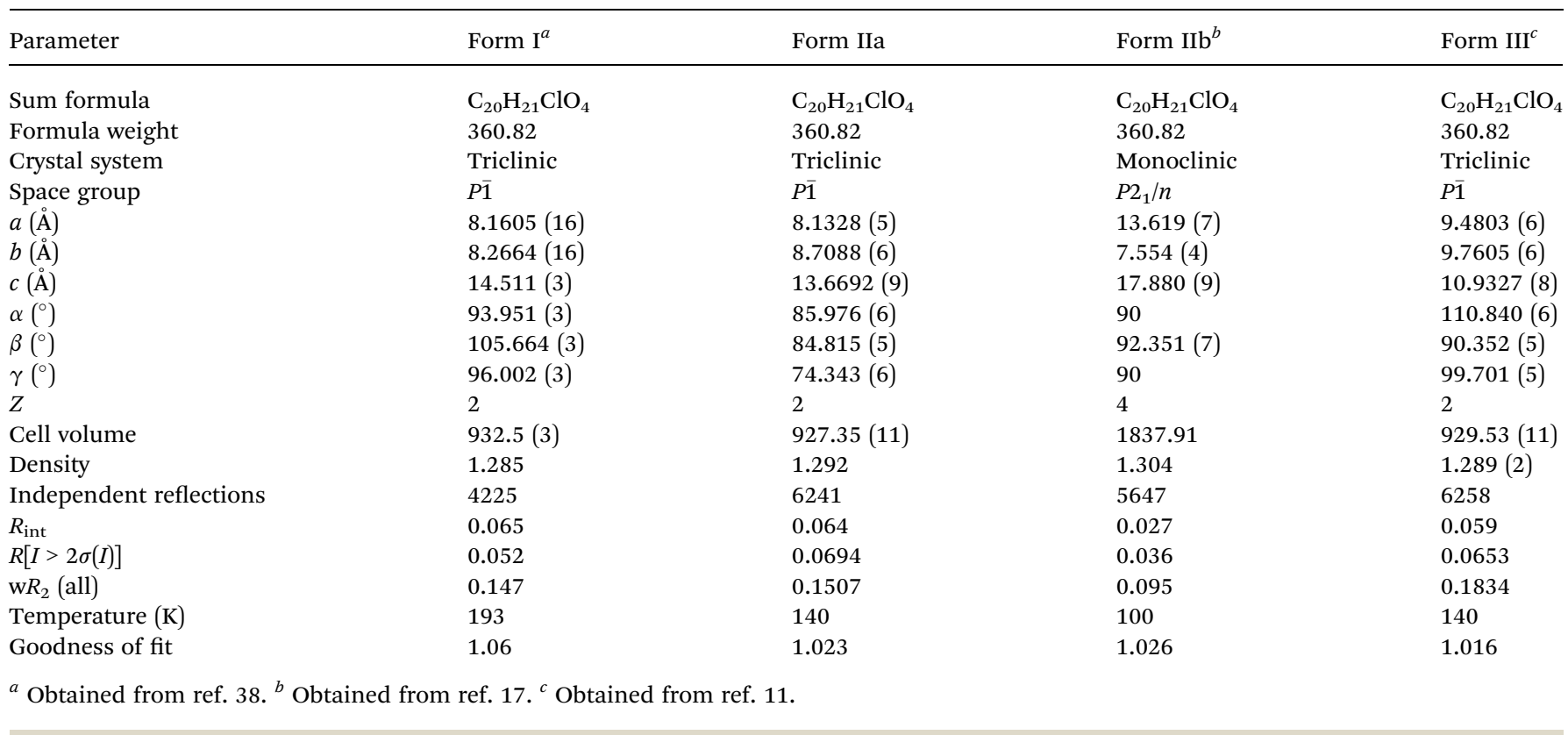

study the morphology of the crystalline FEN. The microscope was controlled from Software Studio Capture 1.6 from Mettler Toledo Ltd (Greifensee, Switzerland). The growth rate of FEN was analysed by using ImageJ software. The average values of three measurements from different images were used. A Hotstage HS82 with a controller by Mettler Toledo Ltd (Greifensee, Switzerland) was used to identify the polymorphic form of the B-FEN $\left(70^{\circ} \mathrm{C}\right)$ by a visual observation of the melting point using a heating rate of $20^{\circ} \mathrm{C} \mathrm{min}^{-1}$.

\section{Attenuated total reflection Fourier transform infrared spectrometry (ATR-FTIR)}

Infrared spectra in this study were acquired by a Bruker IF-66 spectrometer (Bruker Optics, Coventry, UK) equipped with a golden gate MKII accessory from Specac Ltd (Orpington, UK). A few $\mathrm{mg}$ of the sample was placed on the crystal of the ATR cell; each spectrum was acquired at a resolution of $2 \mathrm{~cm}^{-1}$ with 32 scans over a range of 4000 to $550 \mathrm{~cm}^{-1}$ at ambient temperature. For the hot-stage ATR-FTIR, the spectra were acquired every 5 minutes for 3 hours when the sample was placed on the heated ATR stage at $70^{\circ} \mathrm{C}$. The spectra were baseline corrected by using the Bruker OPUS software (Bruker Optics, Coventry, UK). At least three ATR-FTIR spectra were acquired from different sites of each sample to ensure homogeneity throughout the sample tested.

\section{Powder X-ray diffraction (PXRD)}

A Thermo ARL Xtra model (Ecublens, Switzerland) X-ray diffractometer was used in this study. The glass cover slips on which the FEN crystals were grown were placed into the sample holder. The crystals were not milled into powder form in order to avoid any polymorphic transformation induced by milling. However, it is worth highlighting that as the samples were not in powder form, orientation effects may affect the diffraction patterns obtained in this study. The X-ray source generated from a copper X-ray tube $(1.540562 \AA)$ set at $45 \mathrm{kV}$ and $40 \mathrm{~mA}$. Data were collected over a $2 \theta$ range of 5 to $50^{\circ}$, with a step size of $0.01^{\circ}$ with 1 second per step. The instrument was operated under ambient conditions.

\section{Single crystal X-ray diffraction}

The fully crystallised OTS-FEN sample, grown at $40^{\circ} \mathrm{C}$, was used for conducting single crystal X-ray diffraction experiments of FEN form IIa. The diffraction experiments were performed using an Oxford Diffraction Xcalibur-3/Sapphire3-CCD diffractometer (Oxford Diffraction Ltd., Oxford, UK) equipped with a graphite monochromator using Mo-K $\alpha$ radiation $(\lambda=0.71073$ $\AA)$. A single crystal was selected from crystals of FEN form IIa which were colourless prisms. This single crystal sample was mounted on a glass fibre under oil and fixed in the cold nitrogen stream on the diffractometer. Intensity data were measured by thin-slice $\omega$ - and $\varphi$-scans at $140 \mathrm{~K}$. The diffraction data were processed using the CrysAlisPro-CCD and -RED programmes. ${ }^{28}$ The structure was solved in SHELXT ${ }^{29}$ using the dual-space approach and refined with SHELXL ${ }^{30}$ as implemented in ShelXle GUI. ${ }^{31}$ The non-hydrogen atoms were refined with anisotropic thermal parameters. Hydrogen atoms were included in idealised positions and allowed to refine isotropically.

\section{Results and discussion}

\section{Verification of form IIs by single crystal structure analysis}

As the polymorphic form is the focus of this study, we first needed to verify the structural difference of the two types of form II. As mentioned earlier, in the literature, form IIa was reported to be obtained by melt-crystallisation. ${ }^{14-16}$ Therefore 

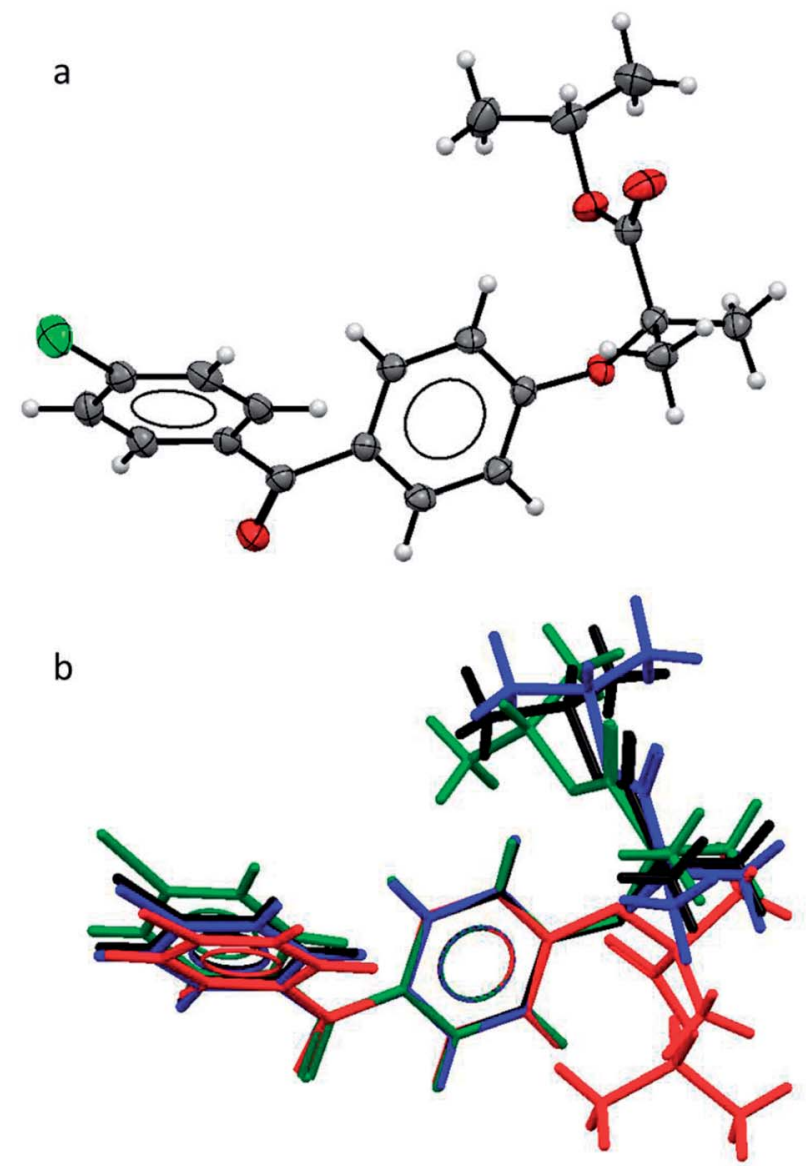

Fig. 1 (a) ORTEP structure of form Ila; (b) an overlay of the molecular conformations in FEN form I (black), form Ila (blue), form Ilb (red), form III (green).

form IIa was prepared by melt-crystallisation and the melting point and FTIR spectra were used to verify the polymorph being the same as the one reported in the literature. The single crystal
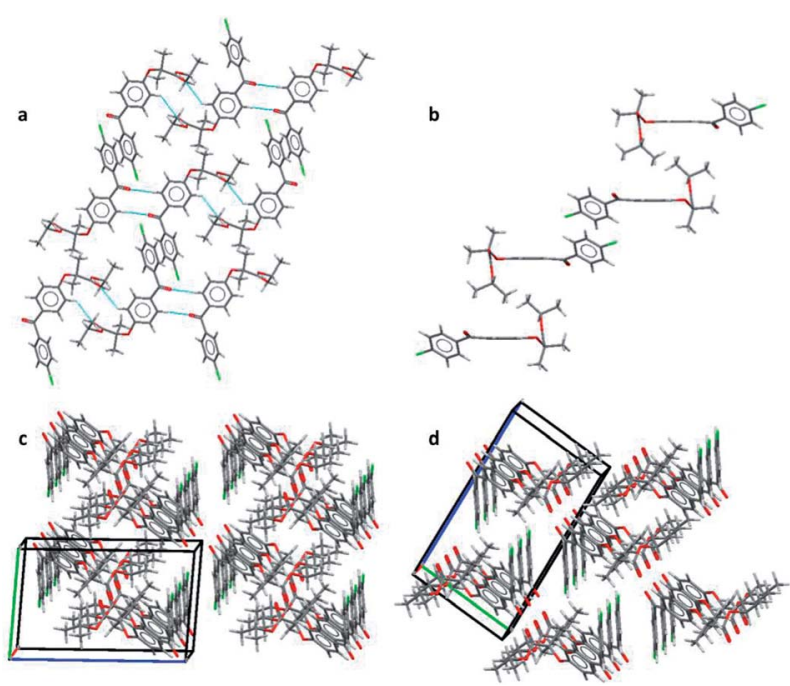

Fig. 2 (a) Layers formed by $\mathrm{CH} \cdots \mathrm{O}$ interactions and $\pi-\pi$ stacking in form Ila; (b) interactions perpendicular to the layers of form Ila; (c) packing diagram of form Ila and (d) packing diagram of form I.
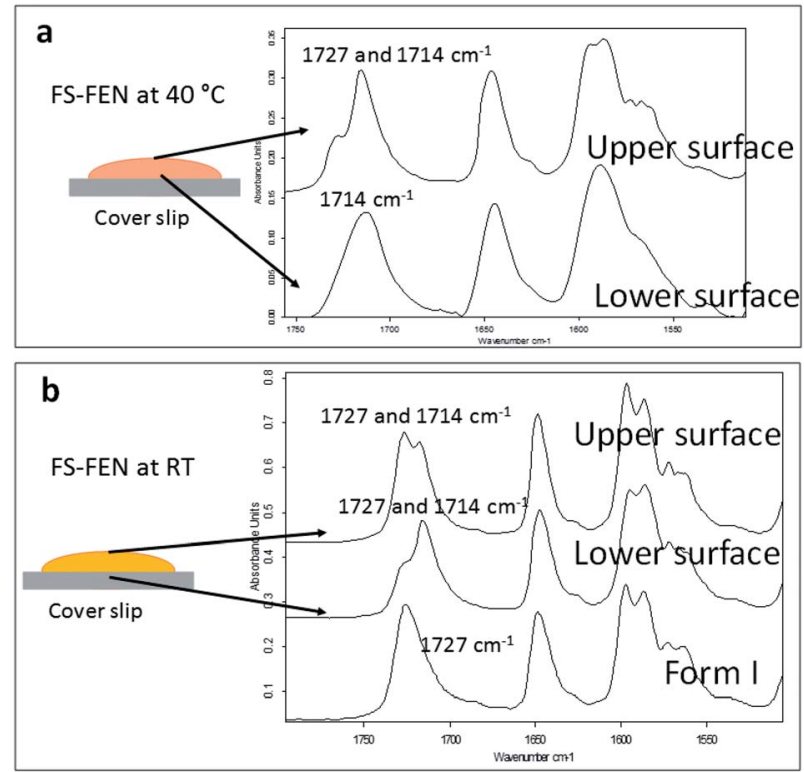

Fig. 3 Partial ATR-FTIR spectra $\left(1760-1500 \mathrm{~cm}^{-1}\right)$ that were acquired on the upper and lower surfaces of (a) FS-FEN $40{ }^{\circ} \mathrm{C}$ and (b) FS-FEN RT. The two carbonyl stretching positions for the $\mathrm{C}_{17}-\mathrm{O}_{3}$ peaks at 1727 and $1714 \mathrm{~cm}^{-1}$ reflect a mixture between FEN forms I and IIa, whereas the carbonyl stretching of $\mathrm{C}_{17}-\mathrm{O}_{3}$ peak at $1714 \mathrm{~cm}^{-1}$ indicates FEN form lla.

structure of form IIa was also determined. The crystallographic parameters of form IIa in comparison with the other known forms are shown in Table 2. The FEN molecule can be divided into two main parts: two aromatic rings linked by a keto group and flexible aliphatic tail. An ORTEP drawing of the molecular structure of FEN form IIa is shown in Fig. 1a. To compare form IIa to the other reported forms (I, III and IIb), their molecular structures were overlaid as illustrated in Fig. 1b. The conformation of FEN in form IIa is largely similar to forms I and III, while the orientation of the alkyl fragment relative to the aromatic rings is markedly different in form IIb. The angles between the planes of the two aromatic rings in forms I, III and IIa are $48.62(7)^{\circ}, 45.73(9)^{\circ}$ and $48.25(10)^{\circ}$, respectively; whereas it is $53.73^{\circ}$ in form IIb. This further confirms that the two form IIs reported in literature are structurally different.

Pairs of molecules in the unit cell of polymorph IIa form dimers linked by $\mathrm{C}-\mathrm{H} \cdots \mathrm{O}$ hydrogen bonds between the ester carbonyl group (O3) and a hydrogen atom of the central benzene ring $(\mathrm{H} 7)[\mathrm{d}(\mathrm{H} \cdots \mathrm{O})=2.662(11) \AA, \angle(\mathrm{C}-\mathrm{H} \cdots \mathrm{O})=$ $135.2(8)^{\circ}$ ]. Two of these hydrogen bonds generate a ring motif between the two molecules of the dimer. The large contact surface area between the two molecules suggests that van der Waals interactions play a significant role in stabilising the dimers (Fig. 2a).

Two principal interactions connect adjacent dimers to form layers parallel to the (111) plane: $\mathrm{C}-\mathrm{H} \cdots \mathrm{O}$ hydrogen bonds and $\pi-\pi$ interactions. The hydrogen bonds occur between an aromatic hydrogen atom in the central ring (H5) and the ketone carbonyl group of an adjacent molecule $(\mathrm{O} 1)[\mathrm{d}(\mathrm{H} \cdots \mathrm{O})=$ $\left.2.570(17) \AA, \angle\left(\mathrm{C}-\mathrm{H}^{\cdots} \mathrm{O}\right)=135.2(8)^{\circ}\right]$ (Fig. 2a). Here again, two 

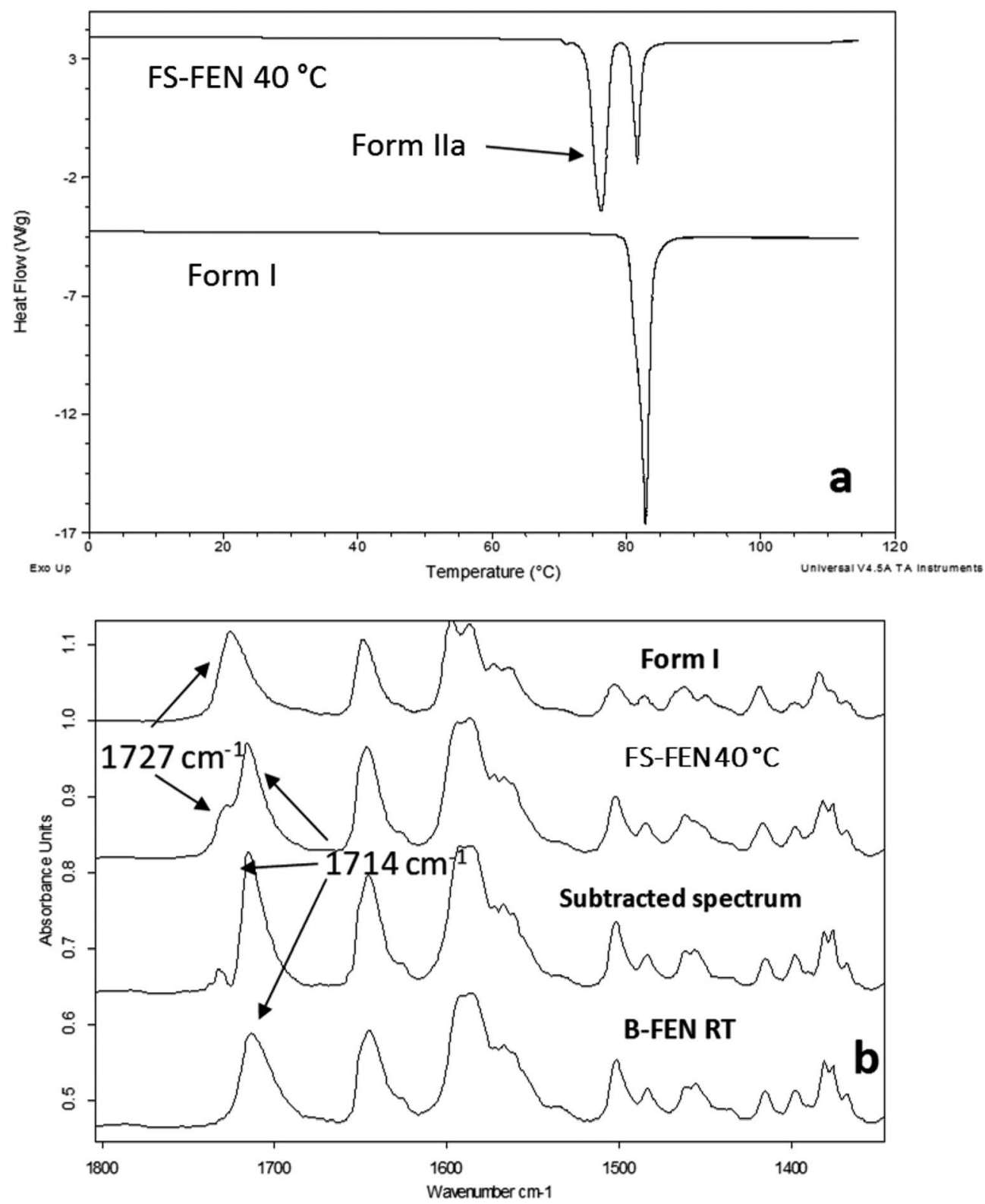

Fig. 4 (a) Melting points of FS-FEN $40{ }^{\circ} \mathrm{C}$ in comparison to the reference form l; (b) partial ATR-FTIR spectra of: reference form l; FS-FEN $40{ }^{\circ} \mathrm{C}$; FS-FEN $40{ }^{\circ} \mathrm{C}$ after subtracting $40 \%$ of the intensity of the form I spectrum; B-FEN crystallised at room temperature.

of these hydrogen bonds form a ring motif. The offset $\pi-\pi$ interaction involves the chlorobenzene fragments of two molecules and takes place at an interplanar distance of 3.3029(8) $\AA$ between the parallel rings (Fig. 2a). The same stacking interaction was observed in form I with an interplanar distance of 3.5116(6) Å.

The most notable interaction between the layers of form IIa involves an 'embrace' of the alkyl groups from molecules in neighbouring layers (Fig. 2b). Interestingly, the same embrace motif is also present in form I, but there it is accompanied by a methyl to ketone $\mathrm{C}-\mathrm{H} \cdots \mathrm{O}$ hydrogen bond. ${ }^{11}$ In form IIa the shortest $\mathrm{H}$ (methyl) $\cdots \mathrm{O}$ (ketone) distance is $3.09 \AA$, much longer than the same contact in form I $(2.56 \AA)$. Nevertheless, the relative arrangement of the molecules remains essentially the same in both forms, suggesting that the favourable packing arrangement of the aliphatic groups is more important than the weak $\mathrm{CH} \cdots \mathrm{O}$ bonds. Combined, the $\pi-\pi$ interactions and the alkyl embrace form infinite slabs of molecules (Fig. 2b), which are shared between forms I and IIa (also see Fig. 8b in (ref. 11)). The resulting similarity in the overall packing structures of both forms can be seen in Fig. 2c and d. This similarity may also explain the sensitivity of the crystallisation process to external stimuli described in the following sections.

\section{Crystallisation and polymorphic transformation of FEN}

The crystallisation of FEN was first studied using the sample melted and cooled on a glass coverslip. As illustrated in Fig. 3a, the FS-FEN crystals grown at $40{ }^{\circ} \mathrm{C}$ at the open top surface (OTS) 

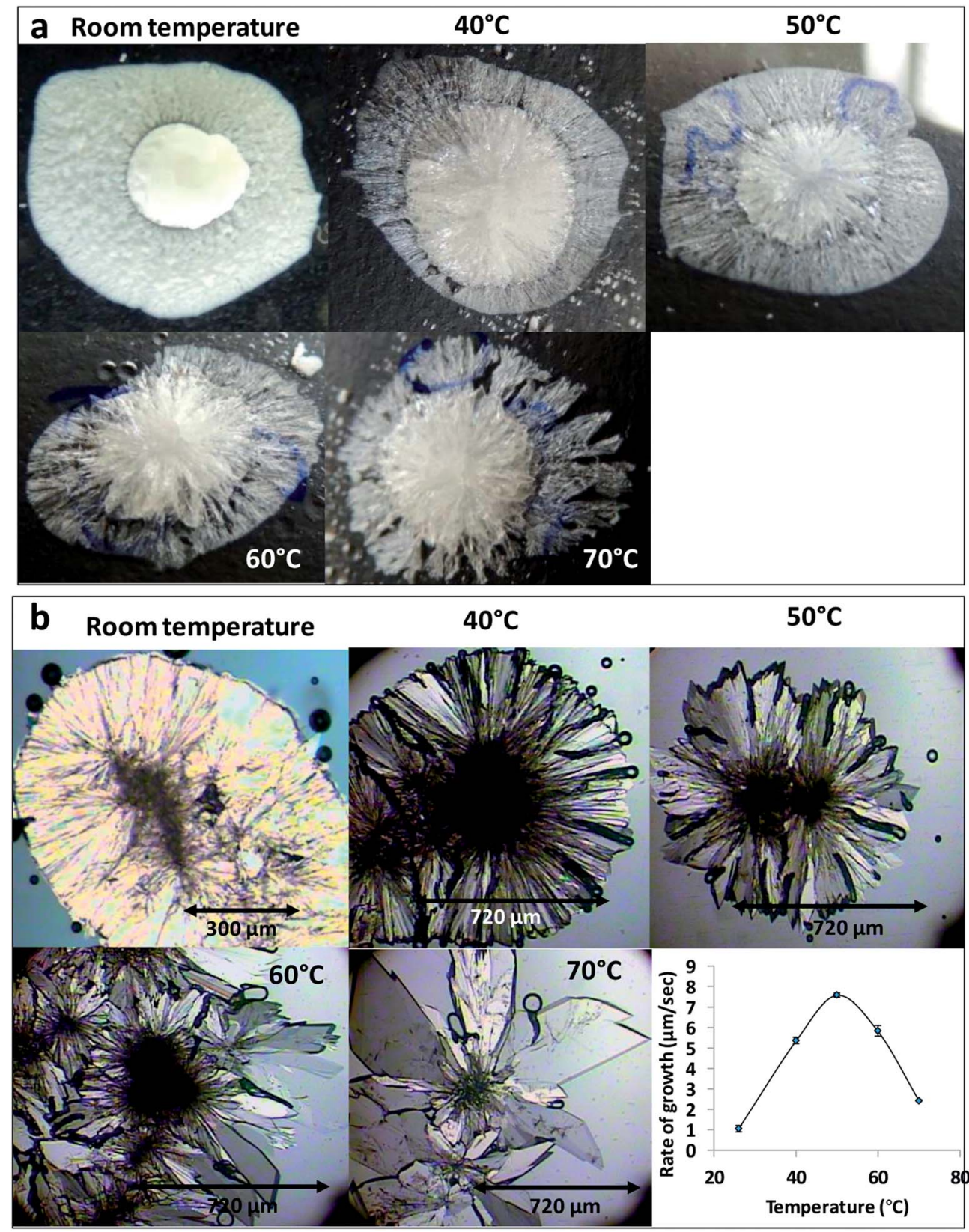

Fig. 5 (a) Optical images of FS-FEN growth at different temperatures and (b) PLM images of B-FEN growth at different temperatures and the change in crystal growth rate associated with the temperature effect.

site showed a $\mathrm{C}_{17}-\mathrm{O}_{3}$ stretching mode at $1727 \mathrm{~cm}^{-1}$ which is a signature peak for form $\mathrm{I}^{\mathbf{1 6}}$ In contrast, the crystals grown at the interface with the glass slide showed a single $\mathrm{C}_{17}-\mathrm{O}_{3}$ stretching peak at $1714 \mathrm{~cm}^{-1}$ which is characteristic of form IIa. ${ }^{16}$ The FS-FEN which crystallised at room temperature showed two $\mathrm{C}_{17}-\mathrm{O}_{3}$ carbonyl stretching peaks (1727 and $1714 \mathrm{~cm}^{-1}$ ) at both the OTS site and the interface with the glass substrate (Fig. 3b). At the OTS site the intensity of the peak at $1727 \mathrm{~cm}^{-1}$ is higher than the $1714 \mathrm{~cm}^{-1}$ peak, indicating that the amount of form I is greater than that of form IIa. However, at the glass interface, the situation is reversed. Some care is needed in the interpretation of intensities, as there may be variations in molar absorptivity, but in the case of similar modes in the same compound a good approximation is that these will vary only slightly. These are the first set of results to indicate that the presence of OTS during the crystallisation of amorphous FEN can impact on the resulting polymorphic form of the drug. Form I preferably grows at OTS and form IIa in the bulk without OTS. This result is in good agreement with other studies, such as the surface crystallisation of indomethacin that led to the generation of a stable gamma polymorph, ${ }^{23}$ and it may be explained by the higher molecular mobility at the OTS, which favours the crystallisation of the thermodynamically more stable polymorph. ${ }^{19-21,26} \mathrm{FEN}$ form IIa shows a preference for the 

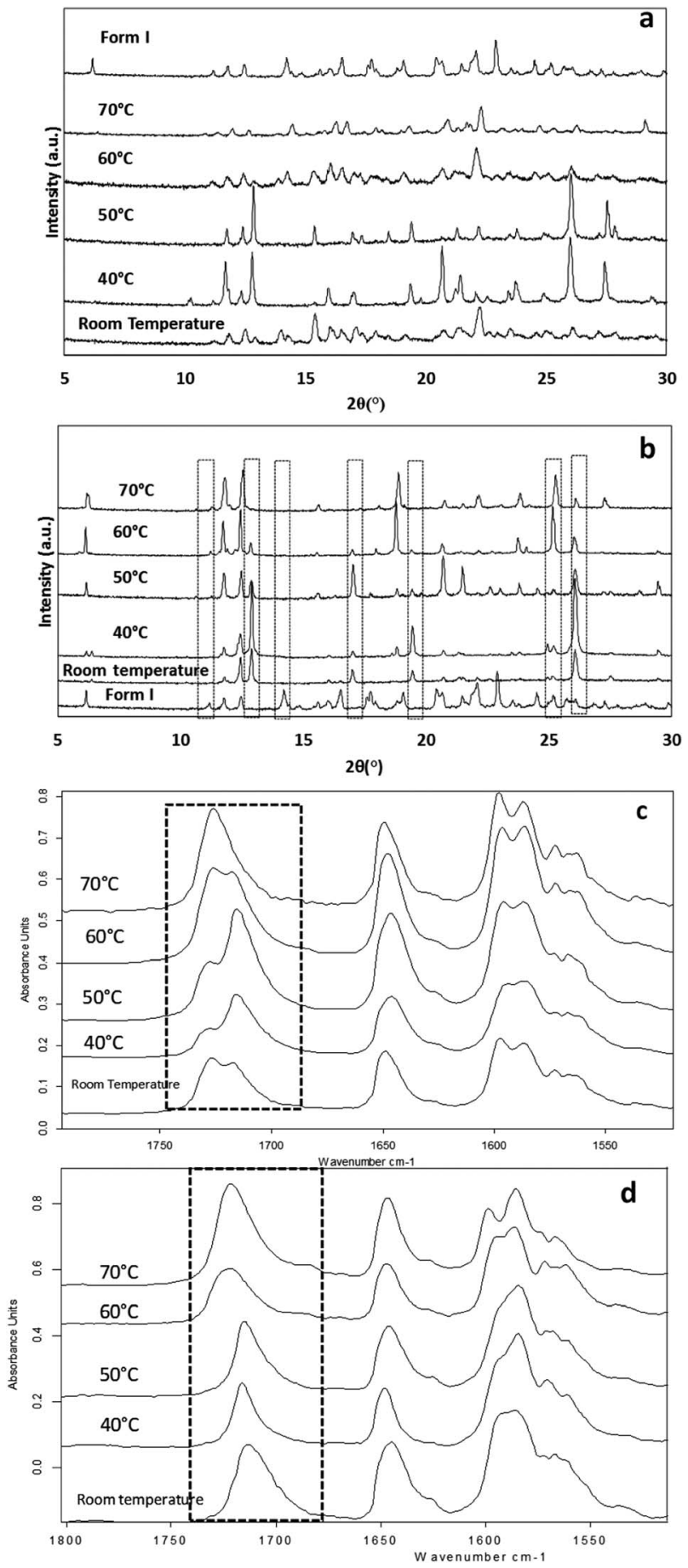

Fig. 6 PXRD patterns of (a) FS-FEN and (b) B-FEN at different crystal growth temperatures and partial ATR-FITR spectra $\left(1800-1500 \mathrm{~cm}^{-1}\right)$ of (c) FS-FEN and (d) B-FEN that were crystallised at various growth temperatures $\left(70,60,50,40^{\circ} \mathrm{C}\right.$ and room temperature).

site at the interface that was in contact with the glass substrate. This phenomenon is likely due to the substrate induced phase (SIP) effect. The SIP effect has been reported to influence the polymorphic form of APIs. ${ }^{23}$ Reischl et al. reported the use of SIP to induce a metastable polymorph of phenytoin. The authors explained that the surface of the substrate has a large effect on the phenytoin crystal alignment that leads to a formation of the metastable polymorph of phenytoin. ${ }^{25}$ Therefore, it is possible to speculate that the origin of FEN form IIa is from the SIP effect of the glass substrate that induces the FEN molecular alignment into the polymorph IIa.

As shown in Fig. 4a, the amorphous FEN, which crystallised at $40{ }^{\circ} \mathrm{C}$ with an OTS (FS-FEN $40{ }^{\circ} \mathrm{C}$ ), had three endothermic melting peaks for FEN at 70,74 and $80^{\circ} \mathrm{C}$. The peak at $70^{\circ} \mathrm{C}$ has an extremely low enthalpy value indicating a trace quantity of this form, which could be a trace of form IIb. However, as the melting point of form IIb was not reported in the literature, this could not be confirmed. The two main melting peaks are the FEN forms IIa and I. ${ }^{14,16}$ The literature does not report the melting enthalpy of the pure FEN form IIa. However, as discussed in the previous section, the single crystal structures of forms I and IIa are similar. It was thus expected that FEN forms I and IIa would demonstrate similar melting enthalpies. This allows the rough estimation of the amount of each form from the melting enthalpy values. The melting enthalpy of form IIa peak is $57.9 \pm 1.8 \mathrm{~J} \mathrm{~g}^{-1}$ whereas form I had a melting enthalpy of $27.9 \pm 5.6 \mathrm{~J} \mathrm{~g}^{-1}$, indicating that form IIa is the dominant polymorphic form under these conditions.

In the B-FEN samples, a different crystallisation behaviour was observed. The ATR-FTIR spectrum of the B-FEN which crystallised between coverslips at room temperature (B-FEN RT) was examined immediately after removing the cover slips with careful avoidance of any other physical contact with the samples. The spectrum is identical with the spectrum of form IIa (Fig. 4b). Therefore, it can be concluded that covering the sample (B-FEN RT) resulted in a significantly increased amount of form IIa crystallisation in comparison to FS-FEN. DSC was not performed on these samples, as the preparation of the sample for DSC requires removal by scratching the crystals off the coverslip and this process is known to induce the conversion of form IIa to form I (Fig. S3†).

\section{Effect of crystal growth temperatures on FS-FEN crystallisation}

The effect of temperature on the crystal growth of FEN was first indicated by the difference between the FS-FEN $40{ }^{\circ} \mathrm{C}$ and FSFEN RT, as discussed in the previous section. Therefore, the effect of temperature on the crystal growth at OTS was studied by storage at room temperature $\left(22^{\circ} \mathrm{C}\right), 40,50,60$ and $70{ }^{\circ} \mathrm{C}$ for 30 minutes immediately after the crystallisation was initiated by scratching. The crystallisation progressed rapidly as reported by Amstad $^{12}$ and within 30 minutes all amorphous samples appeared to be fully crystallised. At room temperature, the continuous growth of fine opaque crystals can be seen underneath the white crystal cluster in the centre where the crystallisation was initiated by mechanical scratching. However, crystal growth at the temperatures of 40,50 and $60^{\circ} \mathrm{C}$ led to the growth of a layer of transparent spherulite crystals beneath the opaque central crystal cluster that was formed first (Fig. 5a). The PXRD patterns of the FS-FEN RT and FS-FEN $60{ }^{\circ} \mathrm{C}$ (Fig. 6a) contain peaks from form I and form IIa peaks that match the ones reported by Di Martino and co-workers. This further 


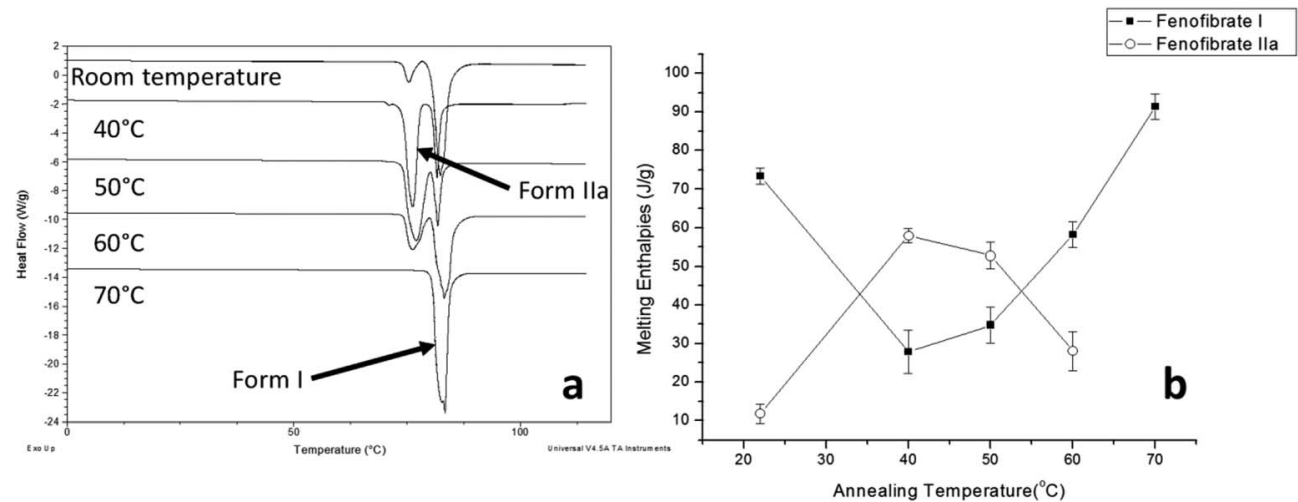

Fig. 7 (a) DSC thermogram demonstrating melting enthalpies of FS-FEN, which were incubated at different temperatures during their crystallisation; (b) changes in the melting enthalpies of FEN forms I and Ila with incubating temperature.

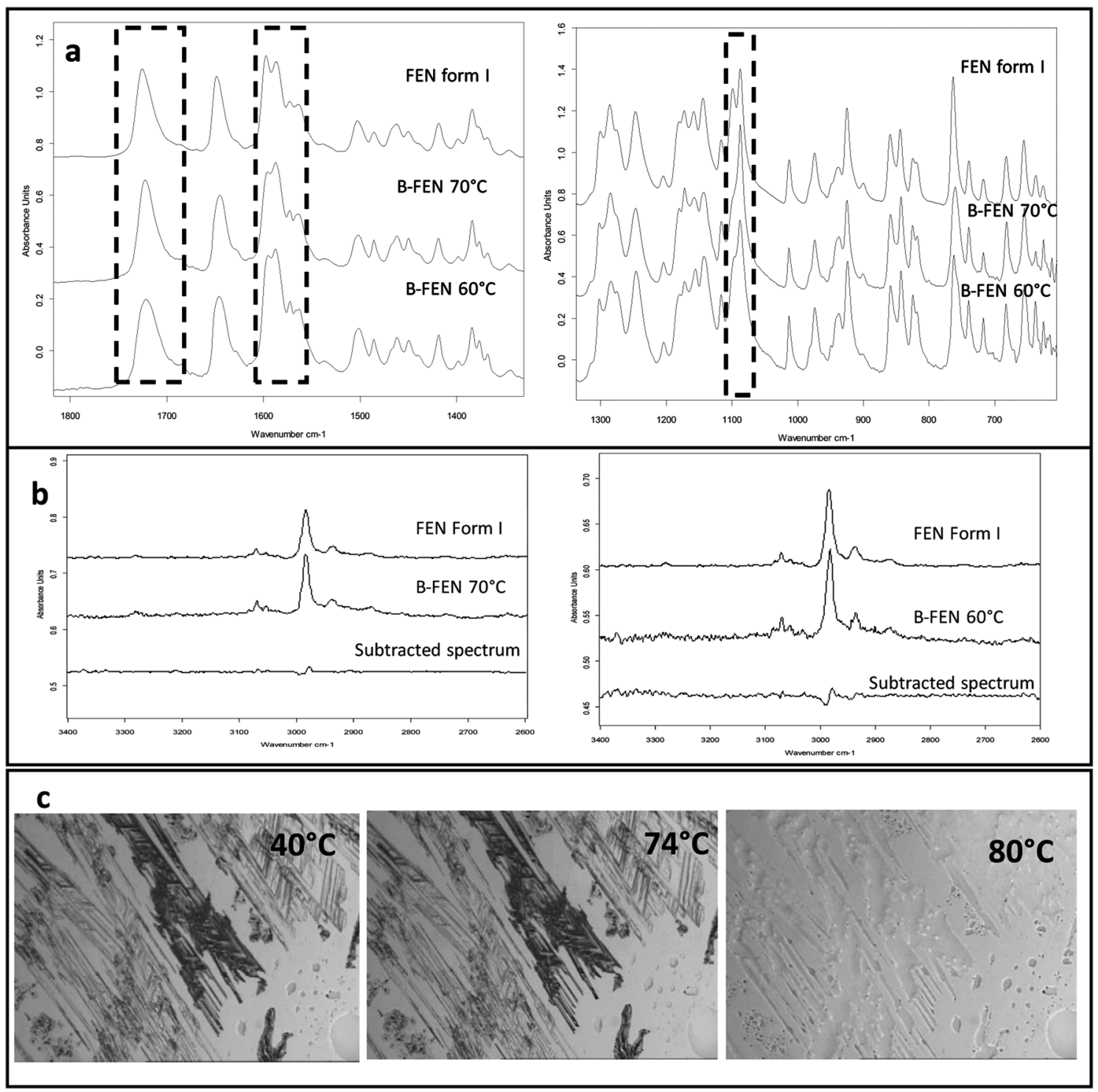

Fig. 8 ATR-FTIR spectra of (a) B-FEN 60 and $70{ }^{\circ} \mathrm{C}$ in comparison to the reference form I spectrum (1800-600 cm $\left.{ }^{-1}\right)$; (b) the subtracted spectra of B-FEN 60 and $70{ }^{\circ} \mathrm{C}$ from the form I spectrum at 3400 to $2600 \mathrm{~cm}^{-1}$; (c) HS-PLM images of B-FEN $70{ }^{\circ} \mathrm{C}$ heated to 40,74 and $80{ }^{\circ} \mathrm{C}$. 


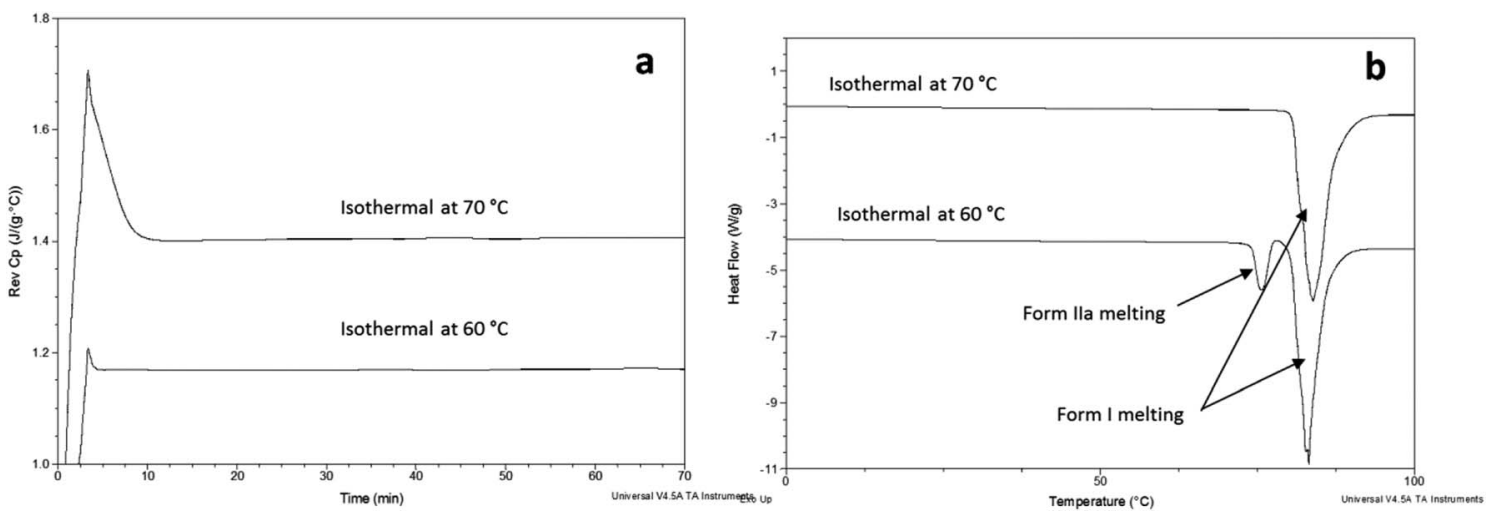

Fig. 9 (a) Isothermal MTDSC thermogram of FS-FEN Ila rich crystals at 60 and $70{ }^{\circ} \mathrm{C}$ for 120 min and (b) DSC heating of a FS-FEN $40{ }^{\circ} \mathrm{C}$ sample after isothermal MTDSC at 60 and $70{ }^{\circ} \mathrm{C}$.

confirms that the crystals were a mixture of forms I and IIa. ${ }^{16}$ The PXRD patterns of the FS-FEN crystallised at 40 and $50{ }^{\circ} \mathrm{C}$ are clearly not pure FEN form I, and most diffraction peaks are at similar positions as those of B-FEN RT, including the diffraction peaks at 12.9, 17.6, 19.5, 26.0 and $27.6^{\circ}$ (Fig. 6b). As B-FEN RT was confirmed being mostly form IIa by ATR-FTIR, this result indicates that more form IIa than form I crystallised at 40 and $50{ }^{\circ} \mathrm{C}$. This is further confirmed by DSC and ATR-FTIR results.

The DSC detected two main melting transitions at 74 and $80{ }^{\circ} \mathrm{C}$ in the FS-FEN samples that crystallised at room temperature, 40,50 and $60^{\circ} \mathrm{C}$, which indicates the co-existence of FEN forms IIa and I and is consistent with the PXRD results (Fig. 7a). The trace amount of possible form IIb with the melting at $70{ }^{\circ} \mathrm{C}$ observed in the FS-FEN at $40{ }^{\circ} \mathrm{C}$ was not identified in the PXRD diffraction pattern due to the low quantity of this material. From the melting enthalpy values, one can obtain a semiquantitative comparison of the amount of form I and form IIa obtained in the samples that were grown at different temperatures (Fig. 7b). At 40 and $50{ }^{\circ} \mathrm{C}$, more form IIa was produced than form I. For the samples grown at room temperature and $60{ }^{\circ} \mathrm{C}$, form I was the dominant polymorph. The ATR-FTIR findings agree with the DSC results. The two ester carbonyl stretching $\mathrm{C}_{17}-\mathrm{O}_{3}$ peaks at 1714 and $1727 \mathrm{~cm}^{-1}$ were observed in the ATR-FTIR spectra of the samples grown at room temperature, 40, 50 and $60{ }^{\circ} \mathrm{C}$, which confirmed the coexistence of form I and form IIa (Fig. 6c). The ester carbonyl peak at $1714 \mathrm{~cm}^{-1}$ was more intense than that at $1727 \mathrm{~cm}^{-1}$, confirming that at 40 and $50{ }^{\circ} \mathrm{C}$ form IIa was the dominant form. In contrast the FS-FEN grown at room temperature and $60{ }^{\circ} \mathrm{C}$ showed a greater intensity of the ester carbonyl peak at $1727 \mathrm{~cm}^{-1}$ indicating the domination of the crystallisation of FEN form I under these conditions.

As the growth temperature was increased to $70^{\circ} \mathrm{C}$, the crystal habits of both the top and bottom surfaces of the growth gradually changed to blade-like shapes, as seen in Fig. 5a. At $70{ }^{\circ} \mathrm{C}$, only form I with a single melting point at $80{ }^{\circ} \mathrm{C}$ was detected by DSC. This was further confirmed by the presence of the single form I ester carbonyl stretching at $1727 \mathrm{~cm}^{-1}$ in the ATR-FTIR spectrum and a form I PXRD diffraction pattern (Fig. 6a).

\section{Effect of crystal growth temperatures on B-FEN crystallisation}

For the B-FEN samples, the crystal morphology changed significantly with changing the growth temperature. At room temperature, the crystals spread rapidly in a symmetrical spherulitic manner during growth. When $40,50,60$ and $70{ }^{\circ} \mathrm{C}$ were used as the crystal growth temperatures, the FEN crystals became a blade-like shape and expanded asymmetrically (Fig. 5b). The crystal growth rate also showed high sensitivity to the changes in the incubation temperature. As seen in Fig. 5b, the crystal growth rates were $1.05,5.37,7.58,5.83$ and $2.4 \mu \mathrm{m}$ $\mathrm{s}^{-1}$ at room temperature $\left(22^{\circ} \mathrm{C}\right), 40,50,60$ and $70{ }^{\circ} \mathrm{C}$, respectively. The maximum crystal growth rate of the FEN was observed at $50{ }^{\circ} \mathrm{C}$. This agrees with Amstad's study that the maximum crystal growth rate of FEN is at $50{ }^{\circ} \mathrm{C} .{ }^{12}$

ATR-FTIR results confirm that the B-FEN crystallisation at 40 and $50{ }^{\circ} \mathrm{C}$ resulted in predominately FEN form IIa (Fig. $6 \mathrm{~d}$ ). The ATR-FTIR spectra of B-FEN 60 and $70{ }^{\circ} \mathrm{C}$ closely resembled the spectrum of FEN form I, but with differences in the ester carbonyl peak which was shifted to $1721 \mathrm{~cm}^{-1}$. There were also slight changes in the intensity of the $\mathrm{C}=\mathrm{C}$ stretch of the benzene ring at 1520 and $1463 \mathrm{~cm}^{-1}$ (Fig. 8a) and the benzene ring in-plane deformation vibration peak at $1098 \mathrm{~cm}^{-1}$ was absent (Fig. 8b). The spectrum subtraction of the B-FEN 60 and $70{ }^{\circ} \mathrm{C}$ from FEN form I was performed by ensuring that the resultant subtracted spectrum had a flat base line in the methyl stretching region $\left(3400-2600 \mathrm{~cm}^{-1}\right)$. This was chosen as the spectra of forms I and IIa do not differ in this region. The subtraction resulted in an intensity close to zero. The small intensities observed are attributed to orientation effects with respect to the refracting ATR crystal resulting in a small apparent peak shift. ${ }^{32}$

The PXRD results also show the changes in the diffraction patterns of B-FEN with changes in the growth temperatures (Fig. 6b). Example diffraction peaks are highlighted in Fig. 6b and they show the clear differences between the known form I and the growth of the B-FEN at different temperatures. The diffraction pattern of B-FEN grown at $40{ }^{\circ} \mathrm{C}$ indicates the crystallisation of mostly FEN form IIa with a small quantity of form I. As the ATR-FTIR data shows no indication of form I, it is likely that the small amount of form I was converted from form IIa 
during the PXRD sample preparation, during which an OTS had to be introduced. The PXRD data of B-FEN grown at $70{ }^{\circ} \mathrm{C}$ PXRD is consistent with FEN form I. In both cases, there are few peaks missing in comparison to the literature data. This is attributed to the orientation effect, which can be seen in both cases with (001) plane as preferred orientation for both forms. PXRD may therefore, not be the most suitable technique to examine the BFEN samples. Hot-stage microscopy was performed to clarify the polymorph of the B-FEN $70{ }^{\circ} \mathrm{C}$ by determining its melting point. The result demonstrated that the B-FEN $70{ }^{\circ} \mathrm{C}$ melts at $80{ }^{\circ} \mathrm{C}$, which is the same as the form I melting point and confirms it being FEN form I (Fig. 8c).

\section{Physical stability of FEN form IIa formed with and without OTS}

FS-FEN $40{ }^{\circ} \mathrm{C}$ was chosen as the representative sample to study the physical stability of FEN form IIa because it contains the greatest amount of the form IIa. The stability was monitored during six months at room temperature using PXRD. There is no clear evidence of the continuous polymorphic transformation of form IIa to I in the mixtures at room temperature (Fig. S1 $\dagger$ ). However, the conversion to form I can be accelerated by applying thermal annealing. Isothermal MTDSC was used to further probe the effect of annealing temperature on the conversion of form IIa to form I. It has been reported previously that a change in the $C_{\mathrm{p}}$ during an isothermal DSC experiment is related to polymorphic conversion. ${ }^{33}$ As seen in Fig. 9a, a more significant surge of the reversing $C_{\mathrm{p}}$ signal was observed at the beginning of the annealing period at $70{ }^{\circ} \mathrm{C}$ than at $60^{\circ} \mathrm{C}$ (completed within $11.3 \pm$ 1.2 minutes for annealing at $70{ }^{\circ} \mathrm{C}$ and $4.8 \pm 0.2$ minutes at 60 ${ }^{\circ} \mathrm{C}$ ). The peak observed in the reversing $C_{\mathrm{p}}$ signal is associated with the polymorphic conversion of form IIa to form I. A standard DSC was used to confirm the nature of the $C_{\mathrm{p}}$ change after the isothermal MTDSC experiment. Only the melting of form I was detected in the FS-FEN $40{ }^{\circ} \mathrm{C}$ samples that had been annealed at $70{ }^{\circ} \mathrm{C}$ (Fig. 9b). This indicates that the change in the $C_{\mathrm{p}}$ is

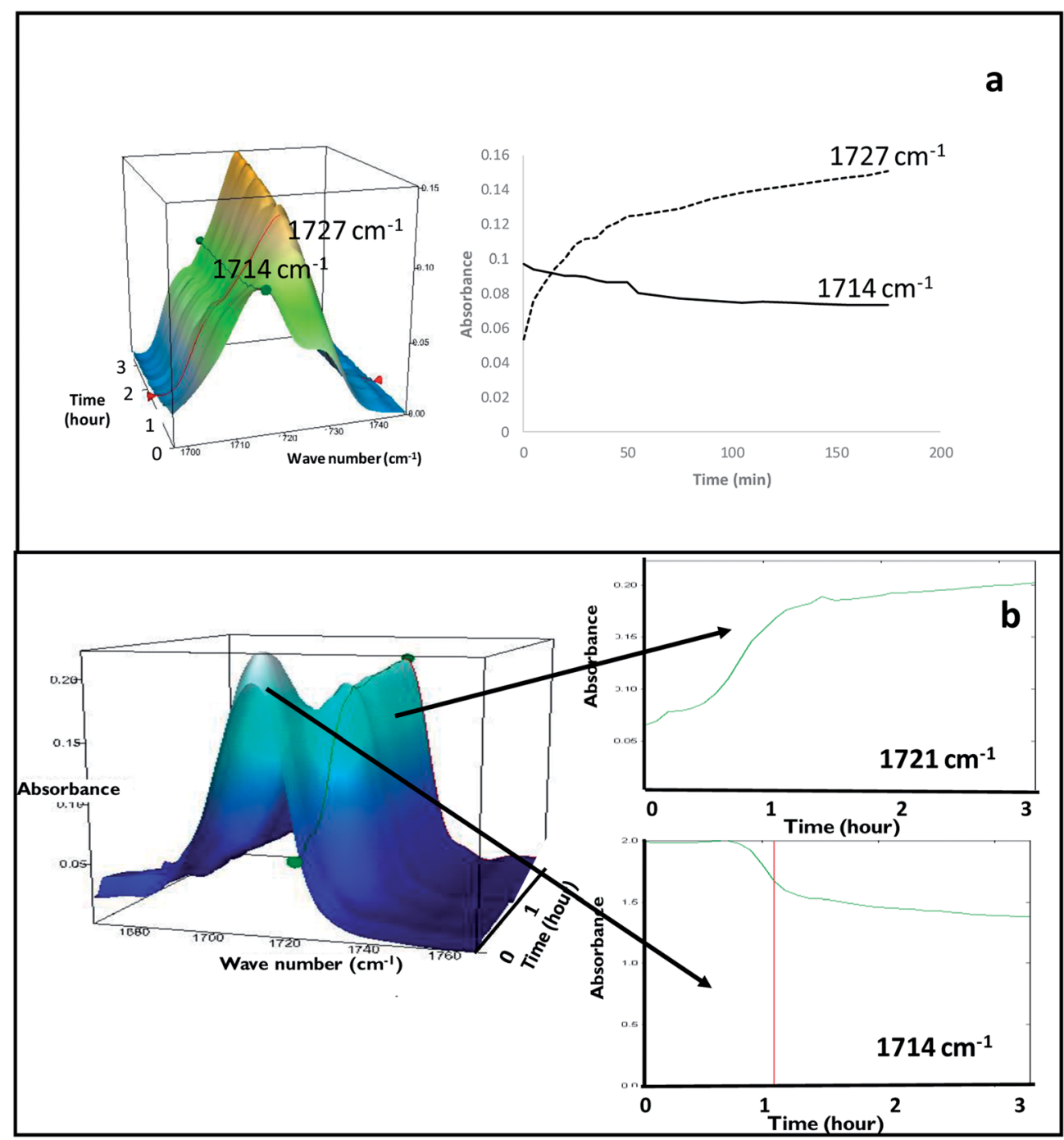

Fig. 10 (a) Peak intensity changes of ester carbonyl stretching peak at $1714 \mathrm{~cm}^{-1}$ (form lla) shifted to $1727 \mathrm{~cm}^{-1}$ (form I) during 3 hours annealing at $70{ }^{\circ} \mathrm{C}$ of FS-FEN $40{ }^{\circ} \mathrm{C}$ indicating the transformation of form lla to form I (b) peak intensity changes in ATR-FTIR spectra of B-FEN after removing coverslips and placing on the variable temperature ATR-FTIR for 3 hours annealing at $70{ }^{\circ} \mathrm{C}$. It should be noted that the characteristic peak of FEN form II at $1714 \mathrm{~cm}^{-1}$ gradually shifted to $1721 \mathrm{~cm}^{-1}$ indicating the polymorphic conversion of form Ila to I. 
associated with the complete polymorphic transformation of form IIa to form I; whereas, the melting of form IIa can still be observed in the sample that annealed at $60^{\circ} \mathrm{C}$, but with a reduced enthalpy value and accompanied by the melting of form I. The reduced enthalpy of FEN form IIa is again associated with an incomplete conversion of form IIa to form I during annealing at $60{ }^{\circ} \mathrm{C}$ (Fig. 9b). Variable temperature ATR-FTIR spectroscopy of the FS-FEN $40{ }^{\circ} \mathrm{C}$ sample that annealed at $70{ }^{\circ} \mathrm{C}$ revealed the transformation of the two ester carbonyl stretching peaks at 1714 and $1727 \mathrm{~cm}^{-1}$ to a single peak at $1727 \mathrm{~cm}^{-1}$ which agrees well with the DSC results confirming the conversion of form IIa to form I (Fig. 10a). A similar transformation occurs when B-FEN is annealed at $70{ }^{\circ} \mathrm{C}$ (Fig. 10b).

For B-FEN samples, after the complete crystallisation at room temperature, PXRD was used to monitor the six-month physical stability of form IIa stored at room temperature. The form IIa is stable for at least six months at room temperature after the top substrate is removed without conversion into form I (Fig. S2 $\dagger$ ). This indicates that at room temperature, form IIa is relatively stable, which is confirmed by the single crystal structural study.

\section{'Switching' of polymorphic form growth}

The conversion of form IIa to form I can be induced by external mechanical stress, such as scratching with a stainless-steel spatula, or thermal treatment (Fig. S3 $\dagger$ ). In addition to this, the significance of OTS on the crystallisation of FEN polymorphic forms from the melt is further demonstrated by a 'switching' effect of the polymorphic growth. It was observed that if there was still non-crystallised amorphous material available in B-FEN samples, removing the cover slip led to the termination of the crystallisation to form IIa, and the growth of form I. As seen in Fig. 11a-c, the continuous growth of FEN form IIa from the melt was observed between coverslips. The spherulite form IIa crystals, which were identified by the ester carbonyl vibration at $1714 \mathrm{~cm}^{-1}$ using ATR-FTIR spectroscopy, expand radially from the nucleation site (initiated by surface scratching) throughout the melt. The removal of the top coverslip before the completion of the crystallisation terminated the expansion of the form IIa (Fig. 11d). Instead, needlelike clusters of crystals could be seen growing rapidly on the edge of the form IIa crystals (Fig. 11e and f). These needle-like crystals were identified as form I by the shift of the ester

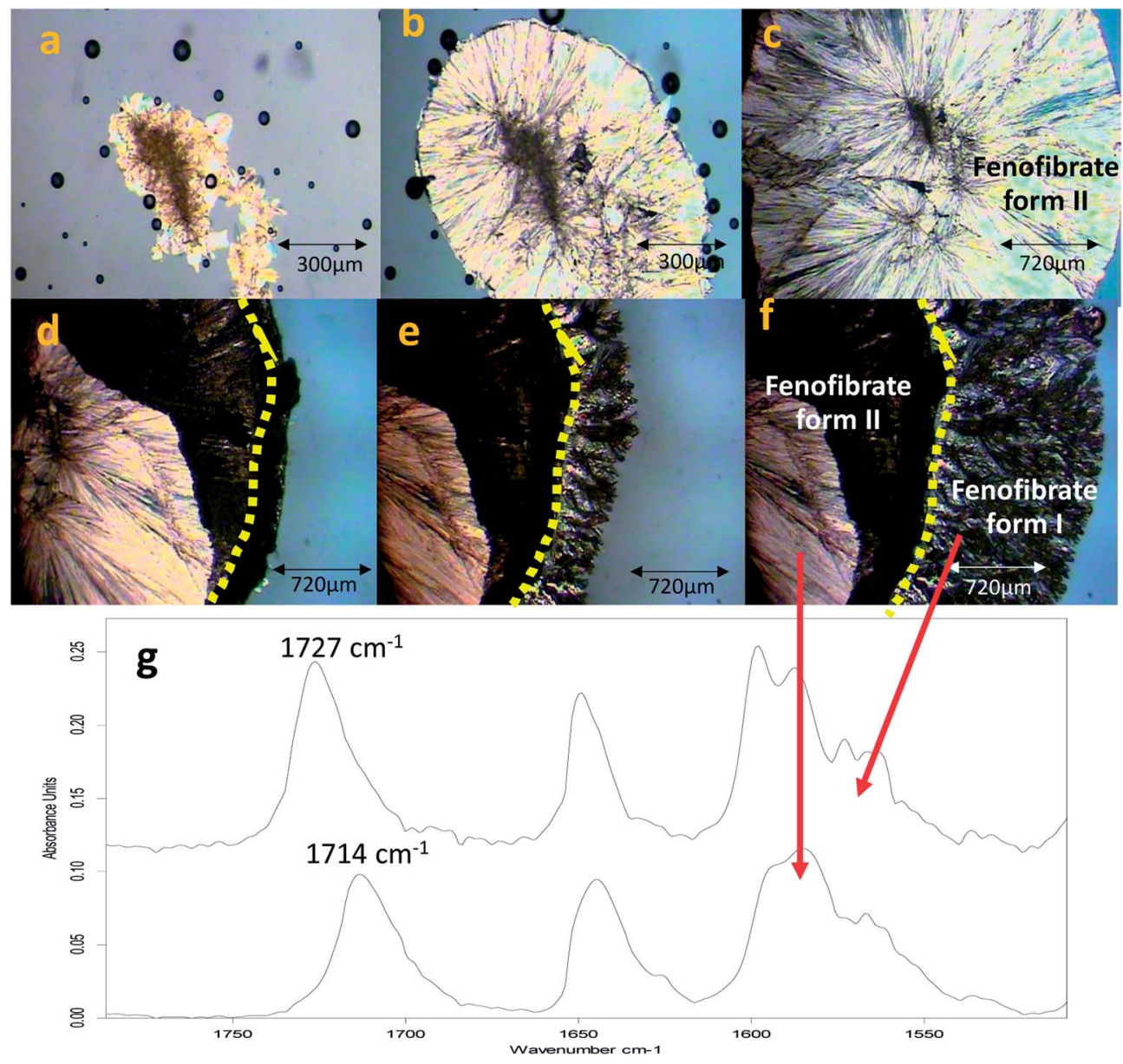

Fig. 11 Images of FEN crystal growth mode being switched from form Ila to form I after top coverslip removal. (a-c) FEN form Ila crystals grown between sandwiched coverslips at room temperature over 17 minutes ( $a=$ initial, $b=5 \mathrm{~min}, c=15 \mathrm{~min}$ ); (d-f) following top cover slip removal, form Ila crystal growth was terminated and form I crystallisation occurred throughout the remaining amorphous FEN ( $d=$ initial, $e=5$ min, $f=15$ $\mathrm{min})$; and (g) spherulite and needle-like crystalline regions were distinguished as two separate domains using ATR-FTIR in which the ester carbonyl stretching peaks at 1714 and $1727 \mathrm{~cm}^{-1}$ indicates the presence of forms Ila and I, respectively. 
carbonyl stretching peak to $1727 \mathrm{~cm}^{-1}$ using ATR-FTIR spectroscopy (Fig. 11g). This phenomenon, in which the crystalline form IIa initiates form I, is likely to be due to cross-nucleation. ${ }^{26,34-37}$ This is a phenomenon in which one crystalline polymorph is nucleated by another polymorph. Tao et al. observed that the seed crystals of mannitol forms $\beta$ and $\delta$ induced the crystallisation of mannitol form $\alpha$ at a temperature below $150{ }^{\circ} \mathrm{C}$. While mannitol form $\beta$ was the only form that crystallised at a temperature greater than $150{ }^{\circ} \mathrm{C}^{26} \mathrm{Gunn}$ et al. reported the crystallisation and growth of nifedipine metastable $\beta$ and $\mathrm{X}$ forms at growth temperatures below $110{ }^{\circ} \mathrm{C}$, whereas pure stable $\alpha$ form of nifedipine was obtained at growth temperatures above $120{ }^{\circ} \mathrm{C.}^{35}$ Hence, the crossnucleation of mannitol and nifedipine is temperature dependent. $^{35,36}$ To the best of our knowledge, this 'switching' effect of the crystal forms provided by the presence of OTS has not been reported previously.

\section{Conclusion}

This study demonstrated that the availability of an OTS during crystallisation is a factor that strongly impacts the polymorphic form selection of the super cooled liquid of FEN. Moreover, the use of a thermal treatment in addition to an OTS can fine tune the selection of the crystallisation of FEN into form I and form IIa. The crystal growth mode switching form IIa to form I occurs when an OTS is introduced to the incomplete crystallisation of form IIa. This indicates that the crystallisation of form I is highly dependent on the OTS. This study reports for the first time the crystallographic data of metastable FEN form IIa, which confirmed the similarity of it to the molecular packing of the stable form I and clarified the confusion between the FEN form IIs in the literature. This study has produced new insights into how to use an OTS to manipulate and control the crystallisation of FEN which will allow improved polymorphic control during crystallisation of FEN.

\section{Conflicts of interest}

There are no conflicts to declare.

\section{Acknowledgements}

The authors would like to acknowledge the IMODE Interreg 2 Seas Cross-border Cooperation Programme for funding. Moreover, we would like to thanks to Dr David Hughes for his kind help with the single crystal X-ray experiments.

\section{References}

1 H. Ling, J. T. Luoma and D. Hilleman, Cardiol. Res., 2013, 4, 47-55.

2 K. Tziomalos and V. G. Athyros, Int. J. Nanomed., 2006, 1, 129-147.

3 P. Buch, P. Holm, J. Q. Thomassen, D. Scherer, R. Branscheid, U. Kolb and P. Langguth, J. Pharm. Sci., 2010, 99, 4427-4436.
4 S. Jamzad and R. Fassihi, AAPS PharmSciTech, 2006, 7, E17E22.

5 H. He, R. Yang and X. Tang, Drug Dev. Ind. Pharm., 2010, 36, 681-687.

6 S. M. Hossen, R. Sarkar, M. H. A. Towhid, M. T. Sultan and N. A. Aziz, J. Appl. Pharm. Sci., 2014, 4, 056-060.

7 T. Patel, L. Patel, T. Patel, S. Makwana and T. Patel, Int. J. Res. Pharm. Sci., 2010, 1, 127-132.

8 P. Srinarong, J. H. Faber, M. R. Visser, W. L. J. Hinrichs and H. W. Frijlink, Eur. J. Pharm. Biopharm., 2009, 73, 154-161.

9 D. Zhou, G. G. Z. Zhang, D. Law, D. J. W. Grant and E. A. Schmitt, J. Pharm. Sci., 2002, 91, 1863-1872.

10 U. Sailaja, M. S. Thayyil, N. S. K. Kumar and G. Govindaraj, J. Pharm. Anal., 2016, 6, 165-170.

11 P. Tipduangta, K. Takieddin, L. Fábián, P. Belton and S. Qi, Cryst. Growth Des., 2015, 15, 5011-5020.

12 E. Amstad, F. Spaepen and D. A. Weitz, Phys. Chem. Chem. Phys., 2015, 17, 30158-30161.

13 S. Watterson, S. Hudson, M. Svärd and Å. C. Rasmuson, Fluid Phase Equilib., 2014, 367, 143-150.

14 P. Di Martino, G. Palmieri and S. Martelli, Die Pharmazie, 2000, 55, 625-626.

15 A. Górniak, A. Wojakowska, B. Karolewicz and J. Pluta, J. Therm. Anal. Calorim., 2011, 104, 1195-1200.

16 A. Heinz, K. C. Gordon, C. M. McGoverin, T. Rades and C. J. Strachan, Eur. J. Pharm. Biopharm., 2009, 71, 100-108.

17 G. K. Balendiran, N. Rath, A. Kotheimer, C. Miller, M. Zeller and N. P. Rath, J. Pharm. Sci., 2012, 101, 1555-1569.

18 T. Cai, L. Zhu and L. Yu, J. Pharma Res., 2011, 28, 2458-2466. 19 Y. Sun, L. Zhu, K. L. Kearns, M. D. Ediger and L. Yu, Proc. Natl. Acad. Sci. U. S. A., 2011, 108, 5990-5995.

20 T. Wu and L. Yu, Pharm. Res., 2006, 23, 2350-2355.

21 L. Zhu, L. Wong and L. Yu, Mol. Pharm., 2008, 5, 921-926.

22 Y. Diao, A. S. Myerson, T. A. Hatton and B. L. Trout, Langmuir, 2011, 27, 5324-5334.

23 A. O. F. Jones, B. Chattopadhyay, Y. H. Geerts and R. Resel, Adv. Funct. Mater., 2016, 26, 2233-2255.

24 B. M. Ocko, X. Z. Wu, E. B. Sirota, S. K. Sinha, O. Gang and M. Deutsch, Phys. Rev. E: Stat. Phys., Plasmas, Fluids, Relat. Interdiscip. Top., 1997, 55, 3164-3182.

25 D. Reischl, C. Röthel, P. Christian, E. Roblegg, H. M. A. Ehmann, I. Salzmann and O. Werzer, Cryst. Growth Des., 2015, 15, 4687-4693.

26 J. Tao, K. J. Jones and L. Yu, Cryst. Growth Des., 2007, 7, 24102414.

27 J. A. Baird, B. Van Eerdenbrugh and L. S. Taylor, J. Pharm. Sci., 2010, 99, 3787-3806.

28 Programs CrysAlisPro, Oxford Diffraction Ltd, Abingdon, UK, 2010.

29 G. M. Sheldrick, Acta Crystallogr., Sect. A: Found. Adv., 2015, 71, 3-8.

30 G. M. Sheldrick, Acta Crystallogr., Sect. C: Struct. Chem., 2015, 71, 3-8.

31 C. B. Hübschle, G. M. Sheldrick and B. Dittrich, J. Appl. Crystallogr., 2011, 44, 1281-1284. 
32 B. H. Stuart, in Infrared Spectroscopy: Fundamentals and Applications, John Wiley \& Sons, Ltd, 2005, pp. 45-70, DOI: 10.1002/0470011149.ch3.

33 S. Qi and D. Q. M. Craig, Mol. Pharm., 2012, 9, 1087-1099.

34 S. Chen, H. Xi and L. Yu, J. Am. Chem. Soc., 2005, 127, 1743917444.
35 E. Gunn, I. A. Guzei, T. Cai and L. Yu, Cryst. Growth Des., 2012, 12, 2037-2043.

36 J. Tao and L. Yu, J. Phys. Chem. B, 2006, 110, 7098-7101.

37 L. Yu, J. Am. Chem. Soc., 2003, 125, 6380-6381.

38 R. Henry, G. Zhang, Y. Gao and I. Buckner, Acta Crystallogr., Sect. E: Struct. Rep. Online, 2003, 59, o699-o700. 